\title{
GRETA's First Years of Work: Review of the monitoring of implementation of the Council of Europe Convention on Action against Trafficking in Human Beings
}

\author{
Julia Planitzer
}

\begin{abstract}
The monitoring mechanism of the Council of Europe Convention on Action against Trafficking in Human Beings (CoE Convention) consists of an independent group of experts (GRETA) and a Committee of Parties. GRETA, which began work in 2009, develops questionnaires for States Parties, reviews their replies and conducts study visits. It then produces a report that is used by the Committee of Parties to make recommendations. This article analyses GRETA's work until November 2011 by assessing the available materials including the questionnaire, the three published replies of States Parties to the questionnaire and the five published final reports on the parties. The objective of the article is to examine the capacity of this process to contribute to enhancing the accountability of States Parties, and to consider whether the application of a human rights-based approach by the parties can, in fact, be effectively monitored. The article also considers the role of civil society in the monitoring process and the ways in which this could be enhanced.
\end{abstract}

Keywords: Council of Europe Convention on Action against Trafficking in Human Beings, implementation of human rights obligations, monitoring of human rights 


\section{Introduction}

In Europe, it is widely agreed that, in order to respond effectively to trafficking in persons, 'a holistic and integrated approach is needed which builds on the respect and promotion of human rights as its fundament' ${ }^{1}$ The Council of Europe Convention on Action against Trafficking in Human Beings (CoE Convention) $)^{2}$ follows a primarily victim-oriented approach that is based on the recognition of trafficking in persons as a violation of human rights. The Convention entered into force in 2008. It includes a mechanism for monitoring the implementation by States Parties of their obligations under the Convention. Based on materials from five monitored States, this article identifies and discusses weaknesses of that monitoring mechanism. The analysis takes into account the GRETA questionnaire, the three published replies of parties to the questionnaire ${ }^{3}$ and the published final reports on the parties. ${ }^{4}$ Additionally, questions concerning the follow up of the implementation and the limited possibilities for the involvement of civil society in the monitoring process are discussed.

\section{Monitoring Mechanism of the Council of Europe Convention on Action against Trafficking in Human Beings}

The central mechanism of the monitoring process of the CoE Convention is GRETA: the Group of Experts on Action against Trafficking in Human Beings. GRETA commenced work in February 2009 and comprises 15 experts who are required to exercise their function independently and impartially. Civil servants are not barred from nomination; only persons holding decision-making positions within the government concerning

1 Report of the EU Experts Group on Trafficking in Human Beings (2004) Brussels,. 63.

2 CETS $N^{\circ} 197$, adopted 3 May 2005, (hereinafter, CoE Convention).

3 Replies from Denmark (GRETA(2011)01), Bulgaria (GRETA(2011)2) and Georgia (GRETA(2011)6) to the Questionnaire for the evaluation of the implementation of the CoE Convention by the parties.

4 Report concerning the implementation of the CoE Convention by Austria GRETA(2011)10), Slovak Republic (GRETA(2011)9), Cyprus (GRETA(2011)8), Albania (GRETA(2011)22) and Croatia (GRETA(2011)20). This article analyses GRETA's work until November 2011 concerning the first group of States Parties within the first evaluation round. 
trafficking in human beings are ineligible. ${ }^{5}$ Nominated by States Parties, the members are elected by the political arm of the monitoring mechanism, the Committee of Parties.

GRETA undertakes its evaluations using three main sources: a questionnaire, which has to be answered by the State Party, information from civil society and subsidiaries, and if necessary, country visits. Based on these various sources of information, GRETA prepares its first draft report. The draft is forwarded to the State Party, which can comment on it. These comments have to be taken into account for the final report. The final report of GRETA is sent to the State Party, which can submit final comments. The final report is published together with the State Party's comments. Finally, the Committee of Parties may adopt recommendations for the State Party and request information about implementation of those recommendations. The evaluation process is organised in rounds, which last for four years each. ${ }^{6}$ Every round has a specific focus chosen by GRETA. Monitoring of the first group within the first round has almost been completed.

\section{GRETA's Work in Practice: A review of the evaluation process and its opportunities and weaknesses}

The monitoring process of the $\mathrm{CoE}$ Convention is unique in the field of trafficking in persons. A recent analysis of monitoring and evaluation mechanisms in the field of anti-trafficking confirms the relative paucity of independent or external evaluation. ${ }^{7}$ For example, the major international treaty on the subject, the United Nations Protocol to Prevent, Suppress and Punish Trafficking in Persons, Especially Women and Children, does not mandate any external evaluation. The

5 Resolution $C M / \operatorname{Res}(2008) 7$ on rules on the election procedure of the members of the Group of Experts on Action against Trafficking in Human Beings (GRETA) (Adopted by the Committee of Ministers on 11 June 2008 at the 1029th Meeting of the Ministers' Deputies), Rule 3.

6 GRETA, Rules of procedure for evaluating implementation of the Council of Europe Convention on Action against Trafficking in Human Beings by the parties, Rule 2, Rules of procedure, THB-GRETA(2009)3.

7 C Hames, et al., Feeling Good about Feeling Bad... A global review of evaluation in anti-trafficking initiatives, Global Alliance Against Traffic in Women, Bangkok, 2010, pp. 10-11. 
mechanism established under the CoE Convention does indeed qualify as an external evaluation mechanism: one that aims at compiling specific information on the integration of the human rights-based approach in actions taken by States Parties against trafficking in persons. Nevertheless, GRETA itself asks rather general questions on this issue which may make it difficult to assess whether this approach is implemented in all spheres of work against trafficking in human beings. ${ }^{8}$

The monitoring system of the CoE Convention can be usefully compared to the monitoring system established under the core UN human rights treaties. ${ }^{9}$ Common features are the existence of an independent expert body; the obligation on States Parties to submit a report to that body (in the case of the CoE Convention, a report containing answers to a questionnaire); and the issuing of concluding observations or recommendations in response to those reports. A clear difference between the monitoring systems, however, is that GRETA can conduct country visits ${ }^{10}$ without requiring specific permission from the State Party. ${ }^{11}$ Additionally, GRETA elaborates its own detailed report while UN treaty monitoring bodies examine the State Party's published report and enters a constructive discussion with that State Party. ${ }^{12}$ Under the CoE Convention, the input from the State Party is not published and there is no public dialogue between GRETA or the Committee of Parties and the State. Moreover, while the UN treaty bodies have generally encouraged and developed guidelines to civil society preparing so-

8 GRETA, Questionnaire for the evaluation of the implementation of the CoE Convention by the parties, GRETA(2010)1 rev, Section I.1 (hereinafter, GRETA questionnaire); C Hames, et al., p. 18.

9 For instance, the Convention on the Elimination of All Forms of Discrimination Against Women, 1249 UNTS 13 (CEDAW), at Article 17-Article 22 and the Optional Protocol to CEDAW, 2131 UNTS 83; Convention on the Rights of the Child, 1577 UNTS 3 (CRC), at Article 43-Article 45; International Covenant on Civil and Political Rights, 999 UNTS 171 and 1057 UNTS 407 (CCPR), at Article 28-Article 45 and the Optional Protocol to CCPR, 999 UNTS 171.

10 Art. 38 (4) CoE.

11 A Gallagher, The International Law of Human Trafficking, Cambridge University Press, Cambridge, 2010, p. 476.

12 M Nowak, Introduction to the International Human Rights Regime, Martinus Nijhoff Publishers, Leiden, 2003, p. 97. See, for instance, Human Rights Committee, Consolidated Guidelines for State Reports under the International Covenant on Civil and Political Rights (26 February 2001) (CCPR/C/66/GUI/ Rev.2), G.1. 
called "shadow" reports, GRETA has not done so. A further, important difference is that most of the UN human rights treaties permit individual complaints from individuals claiming violations of human rights to be received and considered by the relevant treaty body. The CoE Convention does not contain an individual complaints procedure as a further means of monitoring; consequently, GRETA is not endowed with this task.

\section{The GRETA questionnaire}

The evaluation process of the CoE Convention starts with the GRETA questionnaire, which aims to elicit an overview of the implementation of the CoE Convention by the State Party. As a consequence, the questions are fairly general. For example, the GRETA questionnaire asks States Parties whether trafficking in persons is considered a human rights violation in domestic law. Additionally, States Parties have to explain any special legal protection that exists under domestic law in cases of human rights violations. ${ }^{13}$ But the questionnaire does have gaps. For example, while the CoE Convention explicitly requires that parties promote a human rights-based approach in all prevention measures against trafficking in persons,${ }^{14}$ the respective questions do not mention the human rights-based approach and only ask for details on 'social and economic empowerment' for disadvantaged groups. ${ }^{15}$ Similarly, while the CoE Convention requires a child rights approach in all anti-trafficking initiatives or actions, ${ }^{16}$ and also requires a number of child-specific actions, (such as conducting a risk assessment before returning a child), ${ }^{17}$ the questionnaire does not include such considerations. In summary, while the questionnaire is clearly an important tool, it should be strengthened through including more specific questions focusing on State Party implementation of their obligation to integrate an approach based on human rights as well as child rights.

GRETA questionnaire, Questions 4 and 5.

Article 5 (3) CoE Convention.

GRETA questionnaire, Questions 22 and 23.

Preamble, CoE Convention.

Article 16, para. 6, CoE Convention. 


\section{The replies of States Parties to the questionnaire}

The replies of States Parties to the questionnaire could provide important insights. Although the CoE Convention does not pronounce on this point, GRETA decided that the responses must be confidential unless a State Party requests publication..$^{18}$ Only three out of ten States Parties have decided to have their responses published. In comparison with the monitoring of the core UN human rights treaties, the decision to keep replies confidential is disadvantageous for civil society participation. Within the monitoring of UN human rights treaties, State Party reports are indeed published. For example, the Child Rights Convention (CRC) requires parties to make their reports under the CRC widely available in their own country when they are submitted to the monitoring body. ${ }^{19}$ As stated by the Committee on the Rights of the Child, 'unless reports are disseminated and constructively debated (...), the process is unlikely to have substantial impact on children's lives'. ${ }^{20}$ Positive publishing practices are also evident in the context of other CoE conventions. For example, in respect of the European Committee for the Prevention of Torture and Inhuman or Degrading Treatment or Punishment, although reports and comments of the parties are confidential, most parties have chosen to publish these documents. ${ }^{21}$ The confidentiality of State Party responses to the questionnaire hinders early public discussion at the national level. Additionally, if replies were published, civil society could be more focused in their reports to GRETA and in meetings with GRETA during a country visit. In short, States Parties should be encouraged, also by GRETA, to follow the example of Denmark, Bulgaria and Georgia, which have all published the replies.

A closer look into the small number of publicly available replies shows that publication has a positive impact on accountability of States Parties for their obligations under the CoE Convention. For example, States Parties are asked to indicate the budget that is allocated to prevention,

18 Rule 5, Rules of procedure, THB-GRETA(2009)3.

19 Article 44, para. 6, CRC and Committee on the Rights of the Child, CRC/GC/ 2003/5, 27 November 2003, General Comment No. 5, para. 72.

20 Committee on the Rights of the Child, CRC/GC/2003/5, 27 November 2003, General Comment No. 5, para. 71.

21 See: CoE, The CPT in brief, retrieved 8 December 2011, http://cpt.coe.int/ en/about.htm; and Art. 11 of European Convention for the Prevention of Torture and Inhuman or Degrading Treatment or Punishment, CETS $\mathrm{N}^{\circ} 126$, adopted 26 November 1987. 
assistance and protection measures. ${ }^{22}$ The published replies indicate concrete figures. Nevertheless, Denmark excludes amounts spent on prevention since the country is primarily a country of destination or transit and is therefore not spending money in this area. ${ }^{23}$ The States Parties indicate how much is earmarked for the implementation of respective national action plans. ${ }^{24}$ Publishing the allocated budget can support the public demand for increased transparency and accountability of public spending and would offer GRETA the chance to assess the efficiency of initiatives. ${ }^{25}$ GRETA follows up on budgetary questions only partly, but welcomes increased budgets for activities against trafficking in human beings ${ }^{26}$ and calls upon parties to dedicate appropriate funds for actions if there is no specific line in the federal budget. ${ }^{27}$ Additionally, GRETA recommends that States Parties conduct periodic independent evaluations, for instance, in respect of national action plans in order to assess the impact of activities. ${ }^{28}$

As mentioned above, the questionnaire does not include child-specific questions. In relation to the general question on the repatriation of trafficked persons, only Bulgaria described the return and repatriation of children; providing no information about the repatriation of men or women. ${ }^{29}$ Denmark and Georgia do not include any information on this issue in their replies. ${ }^{30}$

22 GRETA questionnaire, Questions 30 and 39.

23 Reply from Denmark to the Questionnaire for the evaluation of the implementation of the CoE Convention by the parties GRETA(2011)01 (hereinafter, Reply from Denmark to the Questionnaire), pp. 23-24.

24 For example, Georgia spends approximately Euro 300,000 (US\$ 403,844) for assistance and protection measures annually; Denmark earmarked Euro 183,000 (US\$ 246,377) for IOM which prepares the return of trafficked persons (three have been repatriated from Denmark in 2008, seven in 2009) and the Bulgarian budget of the National Commission for Combating Trafficking in Human Beings including regional centres and shelters is Euro 151,342.40 (US\$ 203,790.9).

25 C Hames, et al., p. 16.

26 Report concerning the implementation by the Slovak Republic, GRETA(2011)9, para. 97.

27 Report concerning the implementation by Austria, GRETA(2011)10, p. 37.

28 Report concerning the implementation by Croatia, GRETA(2011)20, p. 32.

29 Reply from Bulgaria to the Questionnaire, GRETA(2011)2, p. 35. In 2008, 25 trafficked children returned to Bulgaria; in 2009, 16 children.

30 Reply from Georgia to the Questionnaire, GRETA(2011)6, p. 85. Reply from Denmark to the Questionnaire, GRETA(2011)01, p. 31. 
The questionnaire also requests detailed quantitative data, which would be an opportunity for securing important comparable data in Europe on trafficking in persons. However, the published replies show that the data provided is not complete. For example, all States Parties are required to provide information on compensation for trafficked persons and to indicate how many persons actually received any form of compensation. While States Parties publishing their replies explained the existing legal structure for receiving compensation, no further information (e.g. on cases settled or amounts of compensation provided) was given. ${ }^{31}$ The issue of compensation is usually closely linked to that of the confiscation of the assets of perpetrators. The question of the exact number of judgments leading to the confiscation of perpetrators' assets also remains unanswered..$^{32}$ Another example is the obligation of States Parties to consider not punishing trafficked persons for their involvement in unlawful activities within the trafficking process ('non-punishment clause'). The general application of a 'non-punishment clause' is explained by States Parties. However, concrete information on how many persons actually benefitted from this is not given. ${ }^{33}$ GRETA does seem to follow up missing data in the final reports: for example, recommending improved access to compensation for trafficked persons..$^{34}$ GRETA has also explicitly asked Cyprus whether there have been any cases of confiscation. ${ }^{35}$ With regard to the non-punishment clause, GRETA has noted the need for further measures concerning its effective implementation. ${ }^{36}$

31 GRETA questionnaire, Statistics on Trafficking in Human Beings, T11 and T12.

32 GRETA questionnaire, Statistics on Trafficking in Human Beings, T20, and GRETA(2011)01, p. 46 and 56 and GRETA(2011)2, pp. 50 and 60.

33 GRETA questionnaire, Statistics on Trafficking in Human Beings, T22, and GRETA(2011)01, p. 46 and 57 and GRETA(2011)2, pp. 50 and 60.

34 See, for example, the Report concerning the implementation of the CoE Convention by the Slovak Republic, GRETA(2011)9, p. 38 in which 'GRETA urges the Slovak authorities to take the necessary legislative and practical measures to ensure that compensation is made available to all victims of THB' (hereinafter Report concerning implementation by the Slovak Republic).

35 Report concerning the implementation by Cyprus, GRETA(2011)8, para. 173.

36 See, for example, the Report concerning the implementation by Austria, $\operatorname{GRETA}(2011) 10$, p. 40. 


\section{GRETA's reports on the States Parties}

In addition to the replies of States Parties to the questionnaire, GRETA gathers information from various sources including civil society, as well as from its country visit. All this information is used in the making of the final report. As noted above, this article is based on five such reports. In respect of country visits, those reports show that these are typically conducted by two members of GRETA, accompanied by a member of the secretariat of the CoE Convention.

The reports follow the structure of the questionnaire, but not every question is addressed in the final report. For example, GRETA requires information about social and economic empowerment measures for disadvantaged groups vulnerable to being trafficked. ${ }^{37}$ However, this issue is only discussed in the report on Slovakia-predominantly a country of origin of trafficked persons, according to Slovak authorities. ${ }^{38}$ With respect to this issue, the Slovak report shows that GRETA insists on specific and detailed information and does not accept general or unspecific answers. It also examines the quality of the measures. For example, GRETA found that the provision of general information on a legal act on social services and the inclusion of an activity in the Slovak national action plan against trafficking in persons entitled 'Strengthening of the existing socio-economic measures regarding risk groups of inhabitants against trafficking in human beings based on research outputs on the profile of the THB victims', was not sufficient. GRETA requires more information on what exactly is planned, and recommends implementing more systematic and robust economic, social and educational measures. ${ }^{39}$

Requests for detailed information seem to lead to detailed recommendations. Slovakia, for example, reported on a prevention campaign implemented in cooperation with the International Organization for Migration (IOM), and preventive work in schools and communities implemented by police officers. In commenting on these activities, GRETA stressed that it is 'important that the measures go beyond the "criminal law" understanding of prevention of THB and

GRETA questionnaire, Question 23.

38 Report concerning the implementation by the Slovak Republic, GRETA(2011)9, para. 9.

39 Ibid., para. 66-67. 
aim at creating sufficient awareness among people enabling them to make well-informed decisions concerning employment or migration offers'. ${ }^{40}$ Concerning Austria, GRETA points out that further awarenessraising measures, especially focusing on child trafficking and trafficking for the purpose of labour exploitation, should be implemented and that trade unions and labour and tax inspectors should be targeted, among others. ${ }^{41}$

The issue of follow up-what happens once GRETA's report is finalisedis an important one. To date, the Committee of Parties has recommended that States Parties implement all proposals elaborated by GRETA in its report. ${ }^{42}$ In this respect, it is relevant to note that the CoE Convention's provisions on internal follow up of recommendations appear to be rather weak. According to Article 38(7), the Committee of Parties is only required to set a date for submitting information on the implementation of the recommendations 'if necessary'. The Committee so far has required every State Party to report back on the implementation of the recommendations within two years.

\section{Inclusion of civil society in the monitoring process}

The CoE Convention acknowledges the important role of civil society in many aspects of the national response to trafficking. ${ }^{43}$ It follows that civil society should play a strong role in monitoring. GRETA invited Amnesty International, Anti-Slavery International and La Strada International to a hearing when preparing the first round of evaluation. ${ }^{44}$ In all five final reports, it has stressed that information has also been received from civil society. Each report contains a list of nongovernmental organisations that GRETA met during the country visit. ${ }^{45}$

40 Ibid., para. 56-59.

41 Report concerning the implementation by Austria, GRETA(2011)10, para. 71.

42 Committee of the Parties to the CoE Convention, Recommendation CP(2011)1 (Austria), Recommendation CP(2011)2 (Cyprus), Recommendation CP(2011)3 (Slovak Republic), 6th meeting of the Committee of the Parties, 26 September 2011.

43 See: inter alia Chapter VI of the CoE Convention.

44 GRETA, First General Report on GRETA's activities covering the period from February 2009 to July 2011, GRETA, (2011)11, para. 62.

45 Report concerning the implementation by Cyprus, GRETA(2011)8, p. 46; Report concerning the implementation by Austria, GRETA(2011)10, p. 41; Report concerning the implementation by the Slovak Republic, GRETA(2011)9, p. 40; Report concerning the implementation by Albania, GRETA(2011)22, p. 45; Report concerning the implementation by Croatia, GRETA(2011)20, p. 35. 
Nevertheless, the possibilities for civil society in the monitoring process are restricted. First, information about whether trafficked persons themselves are consulted during the country visits was not provided in the reports. One may conclude that a consultation with victims did not take place throughout the monitoring process. Second, states can include civil society when preparing the reply to the questionnaire, but this is not mandatory. ${ }^{46}$ Out of the three published replies, only Georgia included civil society in the preparation of its response. ${ }^{47}$ Third, the replies are not required to be published, so commenting on the replies for civil society is difficult. In addition, unlike the international human rights treaty bodies, GRETA has not specifically encouraged shadow reporting in order to support its own information gathering, or provided guidance on how this should happen. Noticeably, only a small number of shadow reports were prepared during the first round ${ }^{48}$ and these were not published on the official website of the CoE.

\section{Conclusion}

The existing monitoring process including GRETA and the Committee of Parties allows, to a certain extent, civil society inclusion and, in comparison to other legal instruments regarding trafficking in persons, provides important opportunities for raising the accountability of parties. Nevertheless, the monitoring process needs to be developed further, with the active involvement of monitoring bodies, States Parties and civil society.

GRETA's next questionnaire should focus more specifically on human rights obligations of States Parties to the CoE Convention, with specific reference to their anti-trafficking efforts. It should include, for instance, questions on the non-discrimination principle or on the protection of children's rights. The confidentiality of the parties' replies not only lowers the chance of securing comparable data on trafficking in human beings in Europe, it also clearly impedes the participation of civil society in the monitoring process. Consequently, GRETA should encourage all parties to publish their replies.

46 C Hames, et al., p. 17.

47 Reply from Georgia to the Questionnaire, GRETA(2011)6, p. 5.

48 See, for example, La Strada Moldova, Evaluation of the Implementation of the Council of Europe Convention on Action against Trafficking in Human Beings by the Parties, La Strada, Chisinau, 2010. 
Systematised shadow reporting would greatly support the effective monitoring of the CoE Convention and increase accountability of States Parties. GRETA should, therefore, publicly confirm that shadow reports are welcome, provide a basic structure for such reports and ensure they are published on its website. These steps could motivate more NGOs to provide valuable information. Civil society should continue its work after the formal monitoring process has been completed by using the adopted recommendations for advocacy and by monitoring the State Party's implementation of recommendations.

Julia Planitzer has worked as legal researcher at the Ludwig Boltzmann Institute of Human Rights in Vienna, Austria (http://bim.lbg.ac.at) since 2008. As of 2010, she is also a PhD Fellow at the Doctoral College 'Empowerment through Human Rights', University of Vienna. Her thesis focuses on the implementation of the Council of Europe Convention on Action against Trafficking in Human Beings.

Email: julia.planitzer@univie.ac.at 